\title{
Private Gardens as Urban Greenspaces: Can They Compensate for Poor Greenspace Access in Lower Socioeconomic Neighbourhoods?
}

\author{
Leila Mahmoudi Farahani1 ${ }_{1}^{*}$, Cecily Maller, Kath Phelan 1 \\ 1 RMIT University, Centre for Urban Research, 124 Latrobe Street, Melbourne, VIC, Australia
}

\begin{abstract}
The increasing process of urbanisation has major implications for the environment, biodiversity, and health and well-being of urban residents. Empirical evidence for urban greening benefits suggests that it is an appropriate planning and policy approach for tackling some of the problems associated with urbanisation, including biodiversity loss and heat island effects. Gardens on private residential lots represent a substantial proportion of greenspaces in low density cities with extensive suburban areas. Drawing on a qualitative study of residents in Sunshine North, Melbourne, Australia, this paper discusses three questions about the relationship of private gardens to public greenspaces:

1) how does residents' use of private gardens impact their use of other neighbourhood greenspaces;

2) can private gardens address inequality of access to greenspaces in lower income neighbourhoods; and,

3) what does this imply for planning and neighbourhood design?

Contrary to previous research, the findings did not show a meaningful relationship between residents' use of their gardens and local greenspaces, and further, that large yards and gardens do not substitute for poor access to local greenspaces. The paper concludes that policy makers and planners cannot assume private gardens and public greenspaces are interchangeable. While private gardens and local greenspaces can both provide positive benefits to residents, private gardens do not act as a substitute for local greenspaces in neighbourhoods of varying socio-economic status.
\end{abstract}

\section{Keywords:}

greenspaces, private gardens, planning, neighbourhood

*Corresponding author. Email: leila.farahani@rmit.edu.au

(C) The Authors. 2018. Landscape Online. This is an Open Access article distributed under the terms of the Creative Commons Attribution License (http://creativecommons.org/licenses/by/4.0), which permits unrestricted use, distribution, and reproduction in any medium, provided the original work is properly cited. 


\section{Introduction}

Currently half of the world's population lives in urban areas and the United Nations expects this figure to rise to $70 \%$ by 2050 (United Nations, 2014). Global urbanisation processes present a challenge to greenspace preservation in cities due to the decline in the proportional land cover and quality of open spaces (Sivam et al., 2012). As a result of urbanisation and densification, the consumption of land by new residential developments can lead to a loss of greenspaces and can entrench inequalities in access to them (Kabisch et al., 2015). Previous studies suggest that provision and access to greenspaces can ameliorate some of the negative impacts of urbanisation such as social isolation and lack of community support, cognitive performance and psychological well-being (Keniger et al., 2013). Urban greenspaces can also address biodiversity loss and heat island effects. They are a pertinent example of an appropriate land use and planning policy approach to tackle problems associated with urbanisation (Kendal et al., 2012; Smith et al., 2006).

Urban greenspaces are vegetated public and private spaces in cities which are typically categorised by land use and land cover (Kendal et al., 2016). In this paper, private gardens refer to residential gardens in the front and back yards of suburban houses. Private gardens represent a substantial proportion of greenspace in low-density areas - e.g. almost $30 \%$ in Brisbane (Rupprecht \& Byrne, 2014) and are believed to provide benefits similar to public greenspaces for suburban residents including ecosystem services and mitigating heat island effects (Shanahan et al., 2014). According to Cameron et al. (2012), private gardens contribute up to $36 \%$ of the total urban area depending on the age and location of cities.

Evidence shows that access to public greenspacessuch as availability of parks within walking distance from home - has significant benefits and may reduce income deprivation-related health inequalities (Mitchell \& Popham, 2008). Dwelling type, number of storeys and place of residence influence residents' ease of access to public and private greenspaces (Shanahan et al., 2014). For example urban areas with detached houses have larger garden areas compared with other types of housing, particularly higher density forms such as units, townhouses or apartments (Whitford et al., 2001).

Both vegetation quality, such as diversity or native remnant vegetation cover, and quantity such as tree cover are higher in advantaged socio-economic neighbourhoods (Iverson \& Cook, 2000; Luck et al., 2009; Shanahan et al., 2014). Wright Wendel et al. (2012) demonstrate that the provision of and access to public greenspaces can potentially act as an 'equaliser' between urban areas of high and low socioeconomic status. However, what role do private gardens play in addressing social and spatial inequalities? And are they able to complement or even adequately substitute for public greenspaces in neighbourhoods where they may be lacking?

Public and private sector decisions about greenspace distribution across cities can affect residents' quality of life. Improved knowledge about how residents use different types of greenspaces (in this case, private gardens versus public greenspaces) can inform the provision, distribution and design of such spaces. This study investigates how access to private gardens relates to residents' interactions with local parks and other public greenspaces through a case study of a lower socioeconomic suburban neighbourhood in Melbourne, Australia. We explore how residents perceive and use their gardens and local public greenspaces. In particular we examine whether private gardens are able to fill the gap of insufficient local greenspaces in neighbourhoods where access to such spaces is poor.

The following sections of the paper provide an overview of private gardens, inequalities regarding greenspace provision and similarities and differences between private gardens and public greenspaces benefits. The final section draws upon the case study of Sunshine North to investigate the use of private gardens versus public greenspaces. Our findings have important policy implications for addressing socioeconomic biases in inequitable greenspace distribution. Understanding whether accessibility to public greenspaces reduces the need for private greenspaces and gardens is beyond the scope of this study which could be addressed in future research. 


\section{Private gardens in cities}

Urban green infrastructure includes a range of landscape types of varying complexity and morphology including parks, public greenspace, allotments, green corridors, street trees, urban forests, roof and vertical greening and private gardens (Cameron et al., 2012). We use Cameron et al.'s (2012 p. 129) definition of private gardens as "the area adjacent to a private dwelling, which itself is either privately owned or rented" and is not accessible by the general public. Resident autonomy over the garden is a key feature of private gardens, although householders may give the design and maintenance responsibilities to others such as landscape designers, caretakers or professional gardeners.

Private gardens vary in form, function and size. They may measure a few square metres to larger areas of hundreds square metres (Cameron et al., 2012). Garden size is closely associated with housing type and density (Whitford et al., 2001): in a study of five English cities, Loram et al., (2007) found that while terrace houses were the most numerous of three housing types in each of the studied cities, semidetached and detached houses had the highest cumulative area of garden in each city.

In low-density cities with extensive suburban areas, private gardens represent a large proportion of the overall urban green infrastructure network (Cameron et al., 2012; Ghosh \& Head, 2009; Loram et al., 2007). Private residential land in Sydney provides $43 \%$ of foliage cover and $77 \%$ of Australian capital city residences have one or more trees in their private gardens (Kirkpatrick et al., 2011; Lin et al., 2015). More than $50 \%$ of total greenspace in Dunedin, New Zealand comes from private gardens (Mathieu, Freeman, \& Aryal, 2007) and that figure is 35-47\% in England (Loram et al., 2007), where 87\% of houses have access to a private garden (Gibbons et al., 2014). Lin et al. (2015) suggest that residential areas present the largest opportunity for increasing tree cover in cities. Previous research has shown significant health benefits - such as improving mental health and increasing physical activity - are associated with the presence of nature in immediate proximity to residential dwellings (Nauert, 2017; Shanahan et al., 2014). Given the large contribution of private gardens to the total urban greenspace of cities, understanding their provision, benefits and management is critical (Loram et al., 2007).

Although private gardens can be one of the key contributors to urban green infrastructure in lowdensity cities and provide substantial resources for biodiversity and ecosystem services as well as human health and well-being benefits, few studies focus on private gardens as a part of that infrastructure network (Cameron et al., 2012). Loram et al. (2007) suggest that this gap is due to local government and administrative authorities' lack of management and control of private gardens. Systematically gathering data from such fragmented and inaccessible areas is also challenging (Kendal et al., 2012; Loram et al., 2007), especially where limited resources are available for field work and investigation. The relative importance of private gardens within the wider urban green infrastructure is, therefore, complex to measure (Cameron et al., 2012). The following section highlights the unequal distribution of greenspace in urban areas as a prelude to the next section discussing how private gardens compare to public greenspaces, and how they may or may not address gaps in the provision of the latter in cities.

\section{Inequality regarding urban green infrastructure}

Although access to greenspaces is important for human well-being, greenspaces are often inequitably distributed across cities and spatially correlate with socioeconomic variation (Shanahan et al., 2014). The association between a higher proportion of greenspace and better health depends on the degree of urbanity and level of income deprivation in an area (Mitchell \& Popham, 2007). While greenspaces are seemingly accessible, visitation is highly influenced by income, ethno-racial and cultural characteristics, age, gender, (dis)ability, and other axes of difference (Frankel, 2011; Wolch et al., 2014): residents in lower socioeconomic areas have less access to public and private greenspaces (Lin et al., 2015; Pauleit et al., 2005). Previous studies have also 
argued that inequitable distribution of greenspaces is an environmental justice issue (Sister et al., 2010). The presence of greenspaces in neighbourhoods does not guarantee visitation or use. The level of access and the quality, size and type of greenspaces are other important aspects to consider in regard to inequalities accross suburbs.

In addition to better well-being and access, affluent neighbourhoods generally have more extensive tree cover in both public and private greenspaces, whereas lower socioeconomic areas have poorer tree cover (Lin et al., 2015; Pauleit et al., 2005). In Australia, Sydney's higher socioeconomic status suburbs have considerably more tree cover in private gardens and slightly less in public greenspace compared to suburbs of greater disadvantage (Lin et al., 2015). Residents of higher socioeconomic status can potentially afford properties on larger block sizes in neighbourhoods with established trees and more vegetation cover (Kirkpatrick et al., 2007; Martin et al., 2004).

Inequitable distribution of green infrastructure has important implications for the fairness of future investments in greenspaces and the alleviation of inequitable distribution of greenspace in cities should be prioritised in future greening interventions. Planning professionals, policy makers and local authorities need to consider whether they should direct resources towards public greenspaces or further development of land for residential purposes (Lin et al., 2015). In order to maintain the supply of greenspace in cities and prevent further exacerbation of inequities, any loss of private gardens and green coverage caused by densification should be compensated with provision of public greenspaces. However, as Lin et al. note:

"It becomes increasingly difficult to retrofit public green infrastructure into dense urban areas to make up for lost private green infrastructure, leading to a reduction in the overall ecosystem benefits to a city." (Lin et al., 2015, p. 953).

Understanding how people use private gardens versus public greenspaces and how different types of greenspaces benefit residents in different ways can inform future greening policies and strategies that seek to ameliorate differences between areas of varying socioeconomic advantage. The following section investigates the differences and similarities between private gardens and public greenspaces in the literature.

\section{Private gardens versus non-private greenspaces}

Densification of urban environments can decrease per capita access to greenspaces (James et al., 2009). New suburbs in Australia have significantly less cumulative areas of private gardens compared to established suburbs (Hall, 2010). With greater urban densification and fewer and smaller private gardens, local public greenspaces will have to provide a wider range of services to residents. The design of these spaces will need to meet multiple needs, particularly in disadvantaged neighbourhoods lacking private gardens (Lin et al., 2015). However, first there is a need to examine whether the benefits of private and public greenspaces are similar and if so, whether they can potentially substitute for each other.

According to previous research, local greenspaces and private gardens provide similar benefits (see Figure 1). These include opportunities for social interactions and enhancing social cohesion (Cheng \& Pegg, 2016; Peters et al., 2010; Shanahan et al., 2015), improving mental health and well-being (Cervinka et al., 2016; Cheng \& Pegg, 2016; Lee \& Maheswaran, 2011; Shanahan et al., 2015), and positively contributing to biodiversity (Cameron et al., 2012; Kong et al., 2010; Qiu et al., 2013; Vickery, 1995). Physical health benefits arise from getting to public greenspaces where residents may use active travel modes (walking, cycling) to access such spaces and they may then engage in further physical activity (Veitch et al., 2015). Gardening also has physical health benefits and is considered a moderate-torigorous form of physical activity but is typically limited to private gardens (Armstrong, 2000). Research has focused more on public greenspaces rather than private gardens in relation to decreasing obesity, diabetes, blood pressure and other illnesses triggered by sedentary lifestyles (Haskell et al., 2007), as well as cooling and air quality benefits (Cameron 
et al., 2012; Tzoulas et al., 2007). Public greenspaces and private gardens also bring socioeconomic benefits to local communities such as increasing house values (Clayton, 2007; Tyrvainen, 1997).

Although Figure 1 demonstrates that there are similar benefits arising from public greenspaces and private gardens, comparing the extent of their benefits and how this impacts health and well-being (as well as other impacts) is complex, and remains a gap in the literature. For example, the extent to which different types of greenspaces contribute to social cohesion or social interaction, and whether one type is more effective than the other, is unclear. While some of the benefits of urban greenspaces can simply be achieved through the availability and presence of greenspaces in neighbourhoods (such as air quality, noise reduction and viewing nature), benefits such as physical activity depend on park visitation and the extent of residents' interaction with such spaces, amongst other factors. In places where most residents have access to public greenspaces but only a small proportion visit greenspaces regularly, visitation rates are strongly associated with individual characteristics, perceptions, preferences and socioeconomic status (Shanahan et al., 2014).
Residents are able to easily access nature in private gardens (Lachowycz \& Jones, 2013). Although not all residents who have private gardens enjoy or have time for gardening, some residents see gardening an activity integral to their everyday life and an opportunity for interaction with nature. Gardening is part of their self-identity which contributes to health and well-being (Cameron et al., 2012; Cheng \& Pegg, 2016), and for some gardening "...is a way of life a holistic approach that may help facilitate a mindbody-spirit connection" (D. Wang \& MacMillan, 2013, p. 154). However, attitudes towards private gardens are not always positive: these spaces may be utilised to park cars or represent additional chores in an already hectic daily life (Cameron et al., 2012). As people age, these perceptions may change with gardening viewed as an enjoyable activity for older people (D. Wang \& MacMillan, 2013), possibly due to increased leisure time. Previous research has shown that some people spend more time gardening when retired (Bhatti, 2006).

Existing research which compares the use and visitation of public greenspaces and the time residents spend in their gardens is very limited. A study of Brisbane residents showed that residents
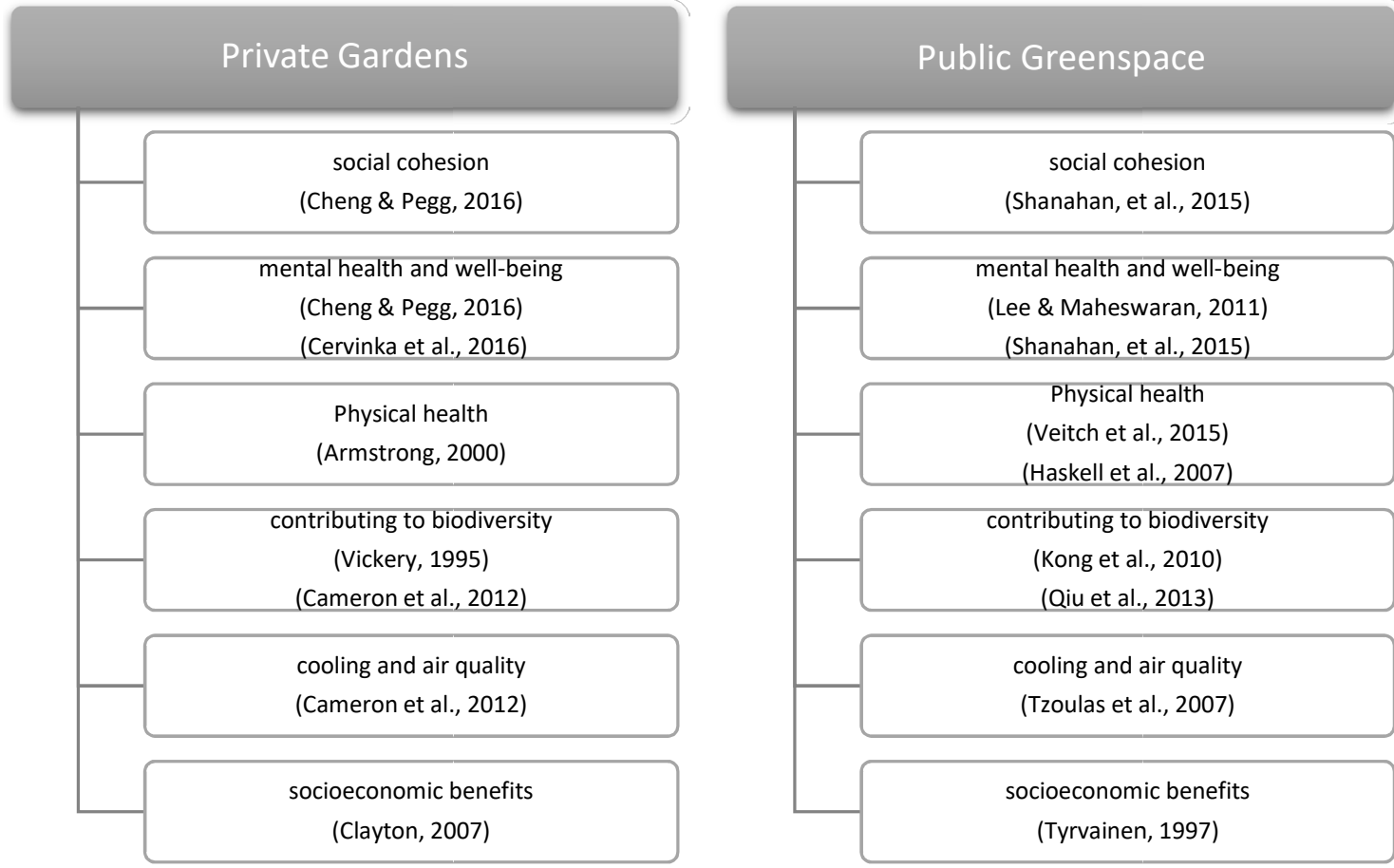

Figure 1: Benefits of public greenspaces and private gardens 
who generally spend more time in parks also spend more time in their private gardens (Lin et al. 2014) However, Lin et al. (2014) conclude that private gardens and public greenspaces are not interchangeable. Another study that investigated whether the presense of public greenspaces can subsitute for a lack of private gardens concluded that functions and meanings attached to private gardens and public greenspaces are different and therefore, the presense of one cannot fulfil the role of the other (Coolen \& Meesters, 2012). Drawing on interviews with residents of Sunshine North, the next section describes a study that explored whether access to private gardens affects or moderates the need for public greenspaces in suburban communities.

\section{Study area and the interview procedure}

The study described here is part of a larger research project conducted by the authors and additional colleagues. An urban greening intervention to transform a section of a concrete stormwater drain in Sunshine North, Victoria, Australia forms the basis of a multi-disciplinary longitudinal study on the impacts of greening interventions on resident health and well-being, and plant and animal biodiversity. This paper reports on a subset of baseline data about local residents' use of their gardens and local greenspaces prior to the urban greening intervention. The area's lack of what participants considered high-quality greenspaces and the presence of large private gardens prompted the research questions discussed in this paper.

Sunshine North, the study area, is located in the western suburbs of Melbourne. Melbourne's climate includes warm, dry and sunny summers from December to Febreurary, mild springs and autumns and cold, wet winters with a mean maximum temperature of $26.5\left({ }^{\circ} \mathrm{C}\right)$ in January and a mean minimum temperature of $5.4\left({ }^{\circ} \mathrm{C}\right.$ ) in July (Australian Bureau Of Meteorology, 2018). Annual average rainfall in Melbourne is around $660 \mathrm{~mm}$.

Located 12 kilometres west of Melbourne's Central Business District, Sunshine North is an established suburb settled after World War II with a population of more than 11,000 people and an average of three people per household (Australian Bureau of Statistics, 2016). With a median weekly household income of AU\$ 882, the area is considered to have low socioeconomic status (Australian Bureau of Statistics, 2016). The study area is a section of Sunshine North bounded by Gilmore Road, Furlong Road and Stony Creek - an urban waterway in Melbourne's western growth corridor that runs through Sunshine North (Fig. 2).

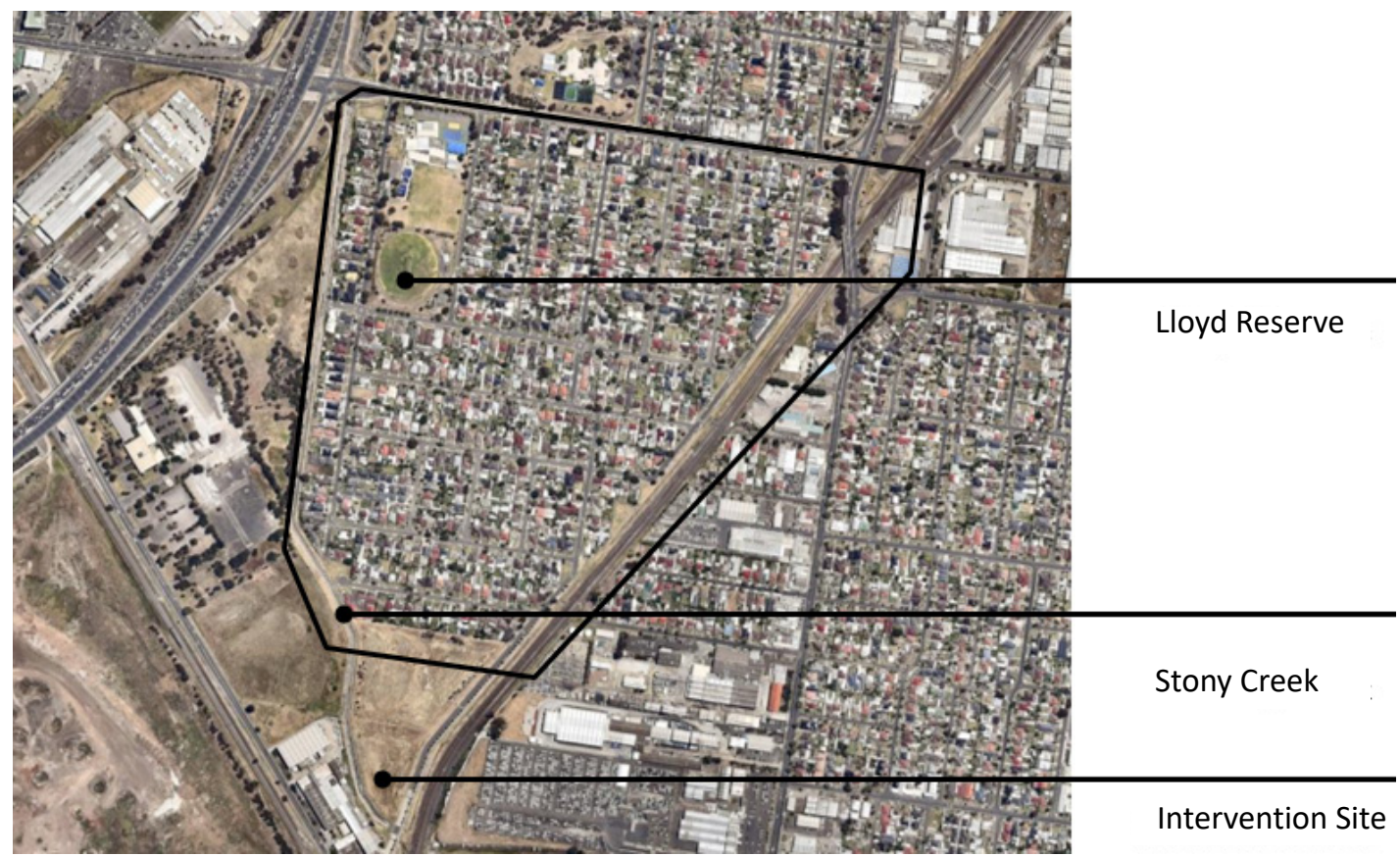

Figure 2: The area under study (Source: Nearmap) 
Residential land parcels in the study area are an average of 600 square metres which potentially can accommodate gardens with established trees and other substantial vegetation (Fig. 3). Similar to other low-density suburban developments, most houses have a front and back yard with lawns, shurbs and trees of different sizes and ages.

Melbourne's western suburbs typically have lower levels of tree coverage and lesser quality green spaces compared to eastern suburbs (Furlong et al., 2017). Public greenspaces in the study area include Lloyd Reserve and an informal greenspace in close vicinity to Stony Creek (which will be transformed into a park through the proposed greening intervention). This section of the creek is currently a concrete channel and the associated open space offers very poor open space amenity (Brimbank City Council, 2015). The site includes a few trees on its boundaries and is mostly covered with native grasses. Lloyd Reserve is the only other greenspace in the study area and is located to the south of the local school. It is about 18,000 square metres and has a sports field in the middle, a few trees on the boundary and a small play ground. It has no benches or sitting spaces. The local government authority, Brimbank City Council, has recently upgraded Lloyd Reserve's sporting facilities which are mainly used by local sports clubs.
The lead author conducted 14 semi-structured interviews with 16 participants (including partners and spouses), during October 2016 - January 2017. The process of recruiting and conducting interviews continued until data themes were 'rich and thick' and data saturation was achieved (Richards \& Morse, 2012). Residents were recruited using flyers delivered to their mailboxes, with participation requiring a Sunshine North residential address and a minimum of 18 years of age. The response rate was three to four percent.

Interviews were between 25 minutes to 105 minutes in duration and addressed residents' use of private gardens including frequency and length of gardening activities. A section of questions focused on residents'perceptions, frequency of visitation and experiences of their neighbourhood greenspaces. Additionally, some questions addressed physical activity, walking attitudes and subjective health and well-being.

A professional transcription service transcribed the interviews' audio recordings and these were imported into Nvivo (qualitative analysis software) for analysis. For the purposes of this paper, the analysis focused on identifying patterns of use and perceptions of greenspaces and private gardens in Sunshine North. Thematic analysis of the interviews facilitated coding of responses into a range of topics.

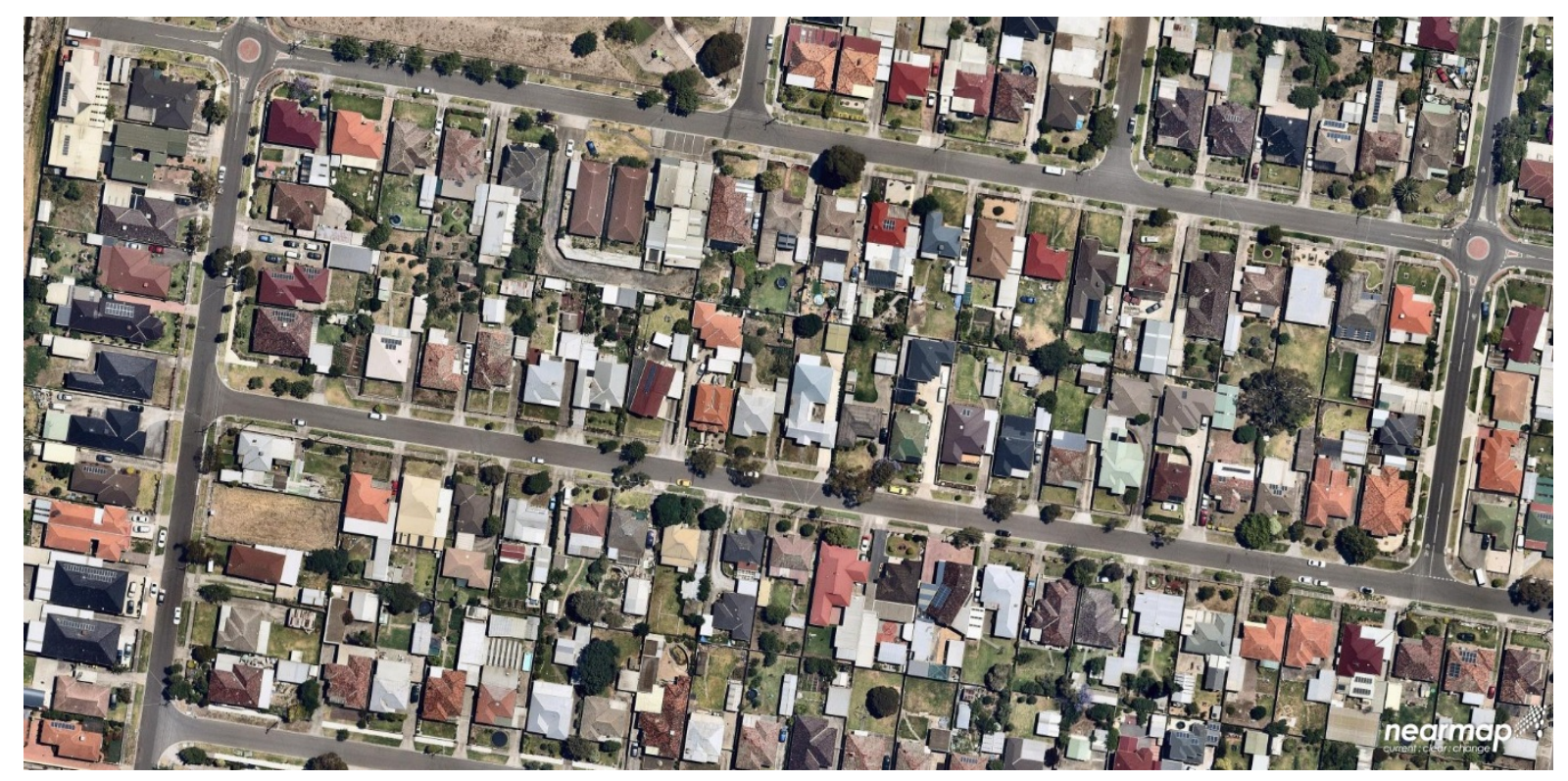

Figure 3: Large plots of land with gardens (Source: Nearmap) 
Table 1: Participants demographic information

\begin{tabular}{|c|c|c|c|c|c|c|c|c|}
\hline Code & Gender & Age & $\begin{array}{l}\text { Years } \\
\text { Lived In } \\
\text { The } \\
\text { Neigh- } \\
\text { bourhood }\end{array}$ & $\begin{array}{l}\text { Home } \\
\text { Ownership }\end{array}$ & Number Of Units & Gardening & Walking & $\begin{array}{l}\text { Greenspace } \\
\text { Visitation }\end{array}$ \\
\hline $1 a$ & Male & $\begin{array}{l}75 \\
\text { Plus }\end{array}$ & 47 & Own & 1 & Very Often & Moderately & Not At All \\
\hline $1 b$ & Female & $\begin{array}{l}75 \\
\text { Plus }\end{array}$ & 47 & Own & 1 & Very Often & Moderately & Moderately \\
\hline 2 & Male & $\begin{array}{l}35- \\
44\end{array}$ & 8 & Own & 1 & Often & Very Often & Very Often \\
\hline 3 & Female & $\begin{array}{l}25- \\
34\end{array}$ & 3 & Rent & 2 & Moderately & Often & Moderately \\
\hline 4 & Female & $\begin{array}{l}35- \\
44\end{array}$ & 13 & Own & 1 & $\begin{array}{l}\text { Small Amount } \\
\text { Of Time }\end{array}$ & Often & Moderately \\
\hline 5 & Female & $\begin{array}{l}35- \\
44\end{array}$ & 9 & Own & 1 & Not At All & Moderately & Moderately \\
\hline 6 & Female & $\begin{array}{l}45- \\
54\end{array}$ & 5 & Own & 1 & Moderately & Very Often & Often \\
\hline $7 a$ & Female & $\begin{array}{l}45- \\
54\end{array}$ & 12 & Own & 1 & Moderately & Moderately & $\begin{array}{l}\text { Small Amount Of } \\
\text { Time }\end{array}$ \\
\hline $7 b$ & Male & $\begin{array}{l}45- \\
54\end{array}$ & 4 & Own & 1 & Moderately & Not At All & $\begin{array}{l}\text { Small Amount Of } \\
\text { Time }\end{array}$ \\
\hline 8 & Male & $\begin{array}{l}65- \\
74\end{array}$ & 60 & Own & 1 & Not At All & $\begin{array}{l}\text { Small } \\
\text { Amount Of } \\
\text { Time }\end{array}$ & $\begin{array}{l}\text { Small Amount Of } \\
\text { Time }\end{array}$ \\
\hline 9 & Female & $\begin{array}{l}65- \\
74\end{array}$ & 54 & Own & 1 & Very Often & Not At All & Not At All \\
\hline 10 & Female & $\begin{array}{l}45- \\
54\end{array}$ & 23 & Own & 1 & Moderately & Often & Moderately \\
\hline 11 & Female & $\begin{array}{l}55- \\
64\end{array}$ & 33 & Own & 1 & Often & Not At All & $\begin{array}{l}\text { Small Amount Of } \\
\text { Time }\end{array}$ \\
\hline 12 & Male & $\begin{array}{l}45- \\
54\end{array}$ & 6 & Own & 1 & $\begin{array}{l}\text { Small Amount } \\
\text { Of Time }\end{array}$ & Often & Moderately \\
\hline 13 & Male & $\begin{array}{l}35- \\
44\end{array}$ & 5 & Rent & 1 & Not At All & Not At All & $\begin{array}{l}\text { Small Amount Of } \\
\text { Time }\end{array}$ \\
\hline 14 & Male & $\begin{array}{l}55- \\
64\end{array}$ & 1.5 & Own & 1 & $\begin{array}{l}\text { Small Amount } \\
\text { Of Time }\end{array}$ & Not At All & Not At All \\
\hline
\end{tabular}


Table one shows that all but one participant had only one house or unit on their block of land, potentially leaving space for gardens. The household with two units also had a backyard with a smaller garden. Participants have lived in the neighbourhood for an average of 20 of years and therefore had a good knowledge of and familiarity with their gardens and the greenspaces in their neighbourhood.

\section{Gardening and its role in everyday lives of residents}

Participants were asked to indicate whether they garden or not. Most participants perceived that gardening played a central role in their lives and brought them pleasure and satisfaction. Some participants spoke of the therapeutic role that their gardens play in their life and how happy their gardens make them. Some residents used the terms 'paradise', 'sanctuary' and 'oasis' to describe their gardens.

"I think because it gets you outside really. You're in the fresh air and you just feel so healthy when you're outside. It makes you feel so much better. If you sit inside, you can do housework all day, but at the end of the day if you haven't been outside you just don't feel as if you've had a good day or a good a day as you could have had" (B, female, 75 plus).

These results are consistent with Cheng and Pegg (2016)'s finding that gardening offers residents a sense of accomplishment and satisfaction through which a deep sense of pleasure and joy can develop. This love of gardens and gardening gave residents a sense of belonging to their home:

"I have no intentions of ever moving. We've done too much to the house and the garden. The garden especially I would, I couldn't ... I won't live long enough to do it all again. For it to be that, that established" $(\mathrm{H}$, female, 55-64 years old).

While most respondents enjoy gardening and find it restorative, others do not enjoy it as much or have time for the upkeep and maintenance. This finding supports previous research on gardening suggesting that it is not enjoyable for all (Cameron et al., 2012). A few residents also mentioned their lack of capability for heavier gardening-related tasks - such as digging - due to health issues or age. One resident expressed concern about water shortages and the amount of water that gardening requires.

"I've probably only lived in suburbia because of the needs of my children, and my financial situation. Um, I would prefer to either live in the country, by the sea, or in the city in an apartment with a balcony in it, a pot plant (laughs). Mowing lawns and you know, upkeep of suburban property, I find quite um boring, but it's just what suits my life right now." (G, female, 35-44 years old).

Therefore, maintaining private gardens was not a popular task for all respondents but does provide enjoyment and satisfaction for some.

\section{Greenspaces: Quality, Access, Distribution and Visitation}

In addition to gardening, participants were asked to indicate their frequency and level of walking in their neighbourhood and how often they visit local greenspaces (Tab.1). Unlike previous studies (Lin et al., 2014), residents who spend more time in their gardens did not have higher rates of public greenspace visitation. However, greenspace visitation was associated with how regularly residents walk in their neighbourhood. As shown in Table 1, some residents walk more regularly around their neighbourhood than visit greenspaces. This may be due to the lack of sufficient or high-quality existing local greenspaces in their neighbourhood.

A few residents were concerned about the unequal distribution of high-quality greenspaces which provide opportunities for different types of activities. Many expressed their dissatisfaction with the quality and number of local parks in their neighbourhood. Residents also talked about accessibility to existing greenspaces: few greenspaces are within walking distance, whereas surrounding suburbs have 
several greenspaces. Half of the participants visit neighbourhood greenspaces on a regular basis (moderately to very often) (see Tab. 1).

A few residents spoke about the lack of greenspaces in Sunshine North and how they have built or reserved their backyards to compensate. However, having large blocks of land and gardens had not lessened participants' preference for what they considered high-quality greenspaces within walking distance. When asked about greenspaces in their locality, residents identified the quality of existing greenspaces as an issue:

"There's just not enough. It's just not enough greenspace, there's not enough planting in the spaces that are available. It's sort of, because the area is so chopped up by the creek, and the train tracks and everything. There's quite a few like odd little, kind of corner blocks, and just spots that obviously either can't be built on, or no one has wanted to. I don't know, they could be planted out. Um yeah, there could just be a lot more greenery" (G, female, 35-44 years old).

When residents were asked what they disliked about greenspaces, most commented on the lack of diversity in the type of existing greenspaces and the facilities and programs they provide. Lloyd Reserve, the only official greenspace in the study area, is a sports field (soccer oval and cricket ground) and residents felt that it had limited opportunities for them:

"Well, we've only really got one park technically, and that's Lloyd Reserve, and that's very much orientated towards sport or there's a small playground there which is great. But for me it doesn't offer me anything; there's no walking track around it, there's no barbeque there, so for me it doesn't offer me anything. The rest of Sunshine North is a lot of service land, so a lot of the land around the railway line isn't actually owned by Brimbank [local government], so they'll just mow the grass every couple of months. So, it's not the tidiest place, or it's not very loved" (C, female, 45-54 years old).
A small number of those interviewed spoke of inequalities regarding greenspace quality and quantity in different suburbs in Melbourne. This case study differs from previous studies on inequality of greenspace distribution in Australia, as Sunshine North households have relatively large gardens compared to other areas with smaller lot sizes but share limited accessibility to public greenspaces. Nonetheless, Sunshine North residents expressed strong concern about inequality in greenspace distribution. One participant referred to Melbourne's eastern suburbs as greener than the west. Another participant observed that other suburbs have beautiful gardens and parks whereas Sunshine North's greenspaces include the railway easement and the Lloyd Reserve:

"I suppose if you compare east to west, yeah, there's not as much greenery or trees over here, but I think that's a circumstance of nature as well, but you can see that there's a lot of people out there from all different uh, groups and societies like there's a Friends of Kororoit Creek that go around planting a lot of trees, there's all different groups trying to green the west. Um, but yeah, it's a lot of hard work. Cuz you just need some bad summers and it all goes back to square one" ( $G$, male, 35-44 years old).

Residents were not satisfied with accessibility to greenspaces outside the immediate neighbourhood. Previous studies have found that residents' use of local greenspaces is determined by actual and perceived accessibility and safety, as well as their perception of how greenspaces should be used (Kessel et al., 2009). A few residents mentioned that they have to drive to access other greenspaces which both contradicts and discourages active transport and use. Participants therefore perceived their accessibility to what they considered high-quality greenspaces, was low:

"We'd hop in the car and go over to Brimbank Park. But the thing is with hopping in the car, defeats, defeats the purpose of going out and just doing something simple as going for a walk. Isn't it? Because you got to load everything up, and you've got to get in the car, and then you 
go, and then you get out of the car, and then you've got to get back in the car" ( $T$, female, 45-54 years old).

As discussed above, all interview participants live in houses with relatively large yards and gardens but most are unhappy with the quality of neighbourhood greenspaces. In most cases, having gardens has not met the residents' expressed desire for sufficient and high-quality local greenspaces to which they can walk and have a range of activities and facilities. Drawing on the lack of sufficient greenspaces in the area, a few of the participants noted that they have created their gardens to compensate for this absence:

"There's just not really anything that's in an easy walking distance...you have to drive to get there. So, there's nothing close to us. So, really, that's why we built our own little oasis. That was it. That's our paradise" ( $H$, female, 55-64 years old).

Another participant referred to residential development and densification and how important public greenspaces are in denser communities where residents do not have their own backyards and gardens:

"I think as time goes on and we have more people living more squashed together, so like all the houses in this area ... Like at the moment, I have a beautiful backyard with lots of plants because I choose to have that. But I could sell this and that backyard would be turned into another house. And even this whole property. The old house could get pulled down and three units, because the council lets three units be built on one block of land now. So, suddenly you've got three families living with no backyard. So, the greenspace becomes so important, because you need somewhere to go. And whether you're a family with little kids, or you're a teenager, or, you know, you mey be a 50 plus lady, you still want somewhere where you can go for a walk or just do something different" (T, female, 45-54 years old).

Participants also identified that the neighbourhood is unappealing for walking or exercise: the area lacks trees and shade, and is generally not inviting. A few residents compared their neighbourhood with suburbs in which they had previously lived and mentioned how they missed their walkability and attractiveness. This lack of perceived walkability intensified a perceived lack of accessibility to greenspaces. As mentioned previously, residents were concerned about greenspaces not being accessible by walking:

"I definitely find that there's not enough greenspaces, there's not enough trees. And $\mathrm{I}$, and I noticed that. Like if I wanted to get exercise and go for a walk, I find it um, quite sad that it's just concrete everywhere and there's not ... You know, if it's a really hot day and you want to get some exercise, there's no shade" ( $M$, female, 35-44 years old).

\section{Discussion}

Private gardens constitute a substantial proportion of greenspaces in suburban cities in Australia and for residents who garden, they have social, psychological, physical, and economic benefits. However, not all residents choose to or are able to garden. Cameron et al.(2012) found that perceptions of private gardens are not always positive: while most participants of this study enjoyed gardening and found it a therapeutic activity, a few participants considered it as a chore for which they do not have time. Residents' benefit from gardens is mostly related to the extent of their gardening practices.

In a review of extant literature, this study found that public greenspaces and private gardens can provide similar benefits to residents. However the extent of their benefits and how residents make use of different types of greenspaces, their different meanings and functions is not yet fully understood. In this regard, the first question this study sought to answer is: how does residents' use of private gardens impact their use of other neighbourhood greenspaces? This study found that residents who spent more time in their gardens did not visit public greenspaces more frequently, which contrasts with Lin et al. (2014) who 
found that residents who visit parks more frequently spend more time in their garden. The present study's findings may be due to residents' dissatisfaction with the quantity and quality of local greenspaces. Individual characteristics of the residents - such as age, gender, ability and cultural background - may also have affected the frequency of greenspace visits (Ozguner \& Kendle, 2006; Schipperijn et al., 2010; Wan \& Shen, 2015; Wang et al., 2016; Zhang et al., 2015). For instance, Payne et al., (2002) have found that age can play a strong role in greenspace visitation and preferences. Other studies have found that the elderly value contact with nature and are attracted to greenspaces with natural elements more than younger adults (Rodiek, 2002; Talbot \& Kaplan, 1991). Ellaway and Macintyre (2001) used a survey to assess gender differences in preferences for greenspaces and found that women are more concerned with greenspace characteristics such as the lack of maintenance and inadequate facilities in these environments. In other studies, gender is found to be a predictor of preferences for natural or designed landscape, where women prefer more natural greenspaces (Caula et al., 2009; Ode et al,. 2009). Therefore, the quality and extent to which greenspaces match local residents' preferences and expectations influence greenspace visitation rates (De La Barrera et al., 2016; Lin et al., 2014). To comprehensively answer the first question, future research should investigate different areas with greenspaces of varying quality and consider individuals' characteristics.

Our findings showed that while most participants perceived that gardening played a central role in their lives and brought them pleasure and satisfaction, some do not enjoy it as much or have time for the upkeep and maintenance. Those who liked and had the time and ability for gardening, felt a sense of attachment to their gardens and houses due to the extent of effort and time spent in their establishment and maintanance. Such social values of private gardens might be different to social benefits public greenspaces usually offer.

The second question this research asked is: do private gardens fill the gap of insufficient local greenspaces in neighbourhoods with lower access to such spaces?
Previous research has found that functions and meanings associated with private gardens and public greenspaces are unique (Coolen \& Meesters, 2012). While the lack of public greenspaces may partially be compensated with the presence of private gardens and gardening activities for a few residents, in most cases the presence of private gardens were not considered as a substitute for lack of parks and public greenspaces.

Our findings indicate that owning relatively large yards and gardens are not equivalent substitutes for access to local greenspaces. Sunshine North residents frequently spoke of the lack of high-quality greenspaces in their neighbourhood. In addition, residents were concerned that higher density developments and subsequently less total garden areas will bring increased demand for accessible public greenspaces. Suburban communities with relatively large gardens still need to have adequate access to local greenspaces as each provides different experiences of nature and opportunities for physical and social activities. Our qualitative study suggests that large private gardens in Sunshine North do not compensate for unequal access to public greenspaces. It also showed that walkable access to public greenscapes can impact their frequency of visitation. Lack of perceived walkability in Sunshine North intensified a perceived lack of accessibility to greenspaces.

Previous studies have found that affluent neighbourhoods have higher tree coverage and their residents have better access to greenspaces compared with areas with lower incomes (Lin et al., 2015; Pauleit et al., 2005). Data from the Australian Bureau of Statistics (2016) shows that Sunshine North is a relatively low socioeconomic status area. Some of our participants compared their suburb and its lack of high-quality greenspaces to suburbs with higher quality greenspaces, especially in Melbourne's eastern suburbs which typically have higher income (Australian Bureau of Statistics, 2016). They pointed to the unequal distribution of greenspaces across eastern and western areas of Melbourne (Furlong et al., 2017).

In regard to the third question this paper sought to address about implications for planning and 
neighbourhood design, these results suggest that efforts to improve equal access to greenspaces should focus on public greenspaces rather than green or open space requirements for new residential developments (Plan Melbourne Refresh, 2017), particularly in lower socioeconomic areas. While private gardens and public greenspaces provide several similar benefits to residents, access to private gardens does not adequately compensate for spatial inequalities in the provision and distribution of public greenspaces. Different forms of greenspace also have different meanings and functions for residents, hence private gardens cannot fully replicate the benefits of public greenspaces and vice versa. Ultimately, the provision of both public and private greenspace in cities are important because of their varying benefits to communities; however, whether one or the other is prioritised in planning decisions will depend on the local context, current greenspace distribution and community needs.

\section{Concluding notes}

Urban greenspaces are considered a key soloution to problems associated with increasing urbanisation such as pollution and urban heat island effects (Kendal et al., 2012; Smith et al., 2006). The green infrastructure of cities includes both public and private greenspaces which although different, can both provide positive benefits for residents. This paper sought to investigate the extent to which the presense of private gardens can compensate for the lack of high quality greenspaces in areas of relative socioeconmic disadvantage which have less access to public greenspaces than other parts of the case study metropolitan area.

Findings from our qualitative research showed no connection between time spent in private gardens and public greenspace visitation in a low socioeconomic neighbourhood. Despite living in detached houses with private residential gardens, residents were concerned about accessbility to what they considered high-quality greenspaces, especially when comparing their neighbourhood of Sunshine North to higher income areas of Melbourne. Our research indicates that the lack of access to public greenspaces can not fully be compensated with the presence of private gardens. The implication of such findings for planning policy makers is that they cannot assume that private gardens and public greenspaces are interchangable and that the presence of private gardens reduces the need for public greenspaces. Future greening initiatives should focus on public greenspaces, supporting improved access in neighbourhoods of various socioeconomic status, and especially those at the lower end of the scale.

\section{Acknowledgments}

The authors thank all of the participants in the study for their valuable contributions and insights. This project was supported through funding provided by the National Environmental Science Programme (NESP) of the Australian Government through the Clean Air and Urban Landscapes Hub (CAUL).

\section{References}

Armstrong, D. (2000). A survey of community gardens in upstate New York: Implications for health promotion and community development. Health \& place, 6(4), 319-327. DOI: 10.1016/ S1353-8292(00)00013-7

Australian Bureau Of Meteorology. (2018). Retrieved from http://www.bom.gov.au/climate/averages/ tables/cw_086071.shtml (Date:20.04.2018)

Australian Bureau of Statistics. (2016). Australian Bureau of Statistics. Canberra: ABS.

Bhatti, M. (2006). 'When I'm in the garden I can create my own paradise': Homes and gardens in later life. The Sociological review, 54(2), 318-341. DOI: 10.1111/j.1467-954X.2006.00616.x 
Brimbank City Council. (2015). From Wasteland to Wetland: Upper Stony Creek set for transformation Retrieved from http://www.buzz.brimbank.vic. gov.au/from-wasteland-to-wetland-upper-stonycreek-set-for-transformation (Date:20.06.2017)

Cameron, R. W. F., Blanuša, T., Taylor, J. E., Salisbury, A., Halstead, A. J., Henricot, B., \& Thompson, K. (2012). The domestic garden - Its contribution to urban green infrastructure. Urban Forestry \& Urban Greening, 11(2), 129-137. DOI:10.1016/j. ufug.2012.01.002

Caula, S., Hvenegaard, G. T., \& Marty, P. (2009). The influence of bird information, attitudes, and demographics on public preferences toward urban green spaces: The case of Montpellier, France. Urban Forestry \& Urban Greening, 8(2), 117-128. DOI: 10.1016/j.ufug.2008.12.004

Cervinka, R., Schwab, M., Schönbauer, R., Hämmerle, I., Pirgie, L., \& Sudkamp, J. (2016). My gardenmy mate? Perceived restorativeness of private gardens and its predictors. Urban Forestry \& Urban Greening, 16, 182-187. DOI: 10.1016/j. ufug.2016.01.013

Cheng, E., \& Pegg, S. (2016). "If I'm not gardening, I'm not at my happiest": exploring the positive subjective experiences derived from serious leisure gardening by older adults. World Leisure Journal, 58(4), 285-297. DOI:10.1080/16078055. 2016.1228219

Clayton, S. (2007). Domesticated nature: Motivations for gardening and perceptions of environmental impact. Journal of Environmental Psychology, 27(3), 215-224. DOI:10.1016/j.jenvp.2007.06.001

Coolen, H., \& Meesters, J. (2012). Private and public green spaces: meaningful but different settings. Journal of Housing and the Built Environment, 27(1), 49-67. DOI: 10.1007/s10901-011-9246-5
DeLa Barrera, F., Reyes-Paecke, S., Harris, J., Bascuñán, D., \& Farías, J. M. (2016). People's perception influences on the use of green spaces in socioeconomically differentiated neighborhoods. Urban Forestry \& Urban Greening, 20, 254-264. DOI:10.1016/j.ufug.2016.09.007

Ellaway, A., \& Macintyre, S. (2001). Women in their place: gender and perceptions of neighbourhoods and health in the West of Scotland. In $M$. Stafford, S. Cummins, S. Macintyre, A. Ellaway, \& M. Marmot (Eds.), Gender differences in the associations between health and neighbourhood environment (Vol. 60, pp. 1681-1692). DOI: 10.1016/j.socscimed.2004.08.028

Frankel, L. K. (2011). The relation of life insurance to public hygiene. 1910. Am J Public Health, 101(10), 1868-1869. DOI:10.2105/

Furlong, C., Phelan, K., \& Dodson, J. (2017). Greening the West: Assessment of the functioning and implications of collaborative efforts to achieve urban greening in Melbourne's West. Retrieved from Ghosh, S., \& Head, L. (2009). Retrofitting the Suburban Garden: morphologies and some elements of sustainability potential of two Australian residential suburbs compared. Australian Geographer, 40(3), 319-346. DOI:10.1080/00049180903127754

Gibbons, S., Mourato, S., \& Resende, G. M. (2014). The amenity value of English nature: a hedonic price approach. Environmental and Resource Economics, 57(2), 175-196. DOI:10.1007/s10640013-9664-9

Hall, T. (2010). Goodbye to the Backyard?-The Minimisation of Private Open Space in the Australian Outer-Suburban Estate. Urban Policy and Research, 28(4), 411-433. DOI:10.1080/0811 1146.2010.496715 
Haskell, W. L., Lee, I.-M., Pate, R. R., Powell, K. E., Blair, S. N., Franklin, B. A., . . Bauman, A. (2007). Physical activity and public health. Updated recommendation for adults from the American College of Sports Medicine and the American Heart Association. Circulation. DOI:10.1161/ CIRCULATION.107.18564

Iverson, L. R., \& Cook, E. A. (2000). Urban forest cover of the Chicago region and its relation to household density and income. Urban Ecosystems, 4(2), 105124. DOI:10.1023/A:1011307327314

James, P., Tzoulas, K., Adams, M., Barber, A., Box, J., Breuste, J., . . . Greening, K. (2009). Towards an integrated understanding of green space in the European built environment. Urban Forestry \& Urban Greening, 8(2), 65-75. DOI:10.1016/j. ufug.2009.02.001

Kabisch, N., Qureshi, S., \& Haase, D. (2015). Humanenvironment interactions in urban green spaces - A systematic review of contemporary issues and prospects for future research. Environmental Impact Assessment Review, 50, 25-34. DOI:10.1016/j.eiar.2014.08.007

Kendal, D., Lee, K., Ramalho, C., Bowen, K., \& Bush, J. (2016). Benefits of Urban Green Space in the Australian Context. Retrieved from Melbourne: Kendal, D., Williams, N. S., \& Williams, K. J. (2012). Drivers of diversity and tree cover in gardens, parks and streetscapes in an Australian city. Urban Forestry \& Urban Greening, 11(3), 257265. DOI:10.1016/j.ufug.2012.03.005

Keniger, L. E., Gaston, K. J., Irvine, K. N., \& Fuller, R. A. (2013). What are the benefits of interacting with nature? Int J Environ Res Public Health, 10(3), 913-935. DOI:10.3390/ijerph10030913

Kessel, A., Green, J., Pinder, R., Wilkinson, P., Grundy, C., \& Lachowycz, K. (2009). Multidisciplinary research in public health: a case study of research on access to green space. Public Health, 123(1), 32-38. DOI:10.1016/j.puhe.2008.08.005
Kirkpatrick, J., Daniels, G., \& Davison, A. (2011). Temporal and spatial variation in garden and street trees in six eastern Australian cities. Landscape and Urban Planning, 101(3), 244-252. DOI:10.1016/j.landurbplan.2011.02.029

Kirkpatrick, J., Daniels, G., \& Zagorski, T. (2007). Explaining variation in front gardens between suburbs of Hobart, Tasmania, Australia. Landscape and Urban Planning, 79(3), 314-322. DOI:10.1016/j.landurbplan.2006.03.006

Kong, F., Yin, H., Nakagoshi, N., \& Zong, Y. (2010). Urban green space network development for biodiversity conservation: Identification based on graph theory and gravity modeling. Landscape and Urban Planning, 95(1), 16-27. DOI:10.1016/j. landurbplan.2009.11.001

Lachowycz, K., \& Jones, A. P. (2013). Towards a better understanding of the relationship between greenspace and health: development of a theoretical framework. Landscape and Urban Planning, 118, 62-69. DOI:10.1016/j. landurbplan.2012.10.012

Lee, A. C., \& Maheswaran, R. (2011). The health benefits of urban green spaces: a review of the evidence. Journal of public health, 33(2), 212222. DOI:10.1093/pubmed/fdq068

Lin, B., Fuller, R. A., Bush, R., Gaston, K. J., \& Shanahan, D. F. (2014). Opportunity or orientation? Who uses urban parks and why. PLoS one, 9(1), e87422. DOI:10.1371/journal.pone.0087422

Lin, B., Meyers, J., \& Barnett, G. (2015). Understanding the potential loss and inequities of green space distribution with urban densification. Urban Forestry \& Urban Greening, 14(4), 952-958. DOI:10.1016/j.ufug.2015.09.003 
Loram, A., Tratalos, J., Warren, P. H., \& Gaston, K. J. (2007). Urban domestic gardens (X): the extent $\&$ structure of the resource in five major cities. Landscape Ecology, 22(4), 601-615. DOI:10.1007/ s10980-006-9051-9

Luck, G. W., Smallbone, L. T., \& O'Brien, R. (2009). Socio-economics and vegetation change in urban ecosystems: patterns in space and time. Ecosystems, 12(4), 604. DOI:10.1007/s10021009-9244-6

Martin, C. A., Warren, P. S., \& Kinzig, A. P. (2004). Neighborhood socioeconomic status is a useful predictor of perennial landscape vegetation in residential neighborhoods and embedded small parks of Phoenix, AZ. Landscape and Urban Planning, 69(4), 355-368. DOI:10.1016/j. landurbplan.2003.10.034

Mathieu, R., Freeman, C., \& Aryal, J. (2007). Mapping private gardens in urban areas using object-oriented techniques and very highresolution satellite imagery. Landscape and Urban Planning, 81(3), 179-192. DOI:10.1016/j. landurbplan.2006.11.009

Mitchell, R., \& Popham, F. (2007). Greenspace, urbanity and health: relationships in England. Journal of Epidemiology \& Community Health, 61(8), 681-683. DOI:10.1136/jech.2006.053553

Mitchell, R., \& Popham, F. (2008). Effect of exposure to natural environment on health inequalities: an observational population study. The Lancet, 372(9650), 1655-1660. DOI: 10.1016/S01406736(08)61689-X

Nauert, R. (2017). Neighborhoods with Nature Tied to Better Mental Health. Retrieved from https://psychcentral.com/news/2017/02/27/ neighborhoods-with-nature-tied-to-bettermental-health/116967.html (Date:27.02.2017)
Ode, A., Fry, G., Tveit, M. S., Messager, P., \& Miller, D. (2009). Indicators of perceived naturalness as drivers of landscape preference. Journal of environmental management, 90(1), 375-383. DOI:10.1016/j.jenvman.2007.10.013

Ozguner, H., \& Kendle, A. D. (2006). Public attitudes towards naturalistic versus designed landscapes in the city of Sheffield (UK). Landscape and Urban Planning, 74(2), 139-157. DOI:10.1016/j. landurbplan.2004.10.003

Pauleit, S., Ennos, R., \& Golding, Y. (2005). Modeling the environmental impacts of urban land use and land cover change-a study in Merseyside, UK. Landscape and Urban Planning, 71(2), 295-310. DOI:10.1016/j.landurbplan.2004.03.009

Payne, L. L., Mowen, A. J., \& Orsega-Smith, E. (2002). An examination of park preferences and behaviors among urban residents: the role of residential location, race, and age. Leisure Sciences, 24(2), 181-198. DOI:10.1080/01490400252900149

Peters, K., Elands, B., \& Buijs, A. (2010). Social interactions in urban parks: Stimulating social cohesion? Urban Forestry \& Urban Greening, 9(2), 93-100. DOI:10.1016/j.ufug.2009.11.003

Plan Melbourne Refresh. (2017). Plan Melbourne Refresh, . Retrieved from Melburne: Qiu, L., Lindberg, S., \& Nielsen, A. B. (2013). Is biodiversity attractive?-On-site perception of recreational and biodiversity values in urban green space. Landscape and Urban Planning, 119, 136-146. DOI:10.1016/j.landurbplan.2013.07.007

Richards, L., \& Morse, J. M. (2012). Readme first for a user's guide to qualitative methods: Sage.

Rodiek, S. (2002). Influence of an outdoor garden on mood and stress in older persons. Journal of Therapeutic Horticulture, 13, 13-21. 
Rupprecht, C. D., \& Byrne, J. A. (2014). Informal urban green-space: comparison of quantity and characteristics in Brisbane, Australia and Sapporo, Japan. PLoS one, 9(6), e99784. DOI:10.1371/ journal.pone.0099784

Schipperijn, J., Stigsdotter, U. K., Randrup, T. B., \& Troelsen, J. (2010). Influences on the use of urban green space - A case study in Odense, Denmark. Urban Forestry \& Urban Greening, 9(1), 25-32. DOI:10.1016/j.ufug.2009.09.002

Shanahan, D., Fuller, R. A., Bush, R., Lin, B. B., \& Gaston, K. J. (2015). The Health Benefits of Urban Nature: How Much Do We Need? BioScience, 65(5), 476-485. DOI:10.1093/biosci/biv032

Shanahan, D., Lin, B., Bush, R., Gaston, K. J., Dean, J. H., Barber, E., \& Fuller, R. A. (2015). Toward improved public health outcomes from urban nature. American journal of public health, 105(3), 470-477. DOI:10.2105/AJPH.2014.302324

Shanahan, D., Lin, B. B., Gaston, K. J., Bush, R., \& Fuller, R. A. (2014). Socio-economic inequalities in access to nature on public and private lands: A case study from Brisbane, Australia. Landscape and Urban Planning, 130, 14-23. DOI:10.1016/j. landurbplan.2014.06.005

Sister, C., Wolch, J., \& Wilson, J. (2010). Got green? addressing environmental justice in park provision. GeoJournal, 75(3), 229-248. DOI:10.1007/s10708-009-9303-8

Sivam, A., Karuppannan, S., \& Mobbs, M. (2012). How "open" are open spaces: evaluating transformation of open space at residential level in Adelaide-a case study. Local Environment, 17(8), 815-836. DOI:10.1080/13549839.2012.68 8734
Smith, R. M., Thompson, K., Hodgson, J. G., Warren, P. H., \& Gaston, K. J. (2006). Urban domestic gardens (IX): composition and richness of the vascular plant flora, and implications for native biodiversity. Biological conservation, 129(3), 312322. DOI:10.1016/j.biocon.2005.10.045

Talbot, J. F., \& Kaplan, R. (1991). The benefits of nearby nature for elderly apartment residents. The International Journal of Aging and Human Development, 33(2), 119-130. DOI:10.2190/ XK9Q-3MDL-XYW9-9QL3

Tyrvainen, L. (1997). The amenity value of the urban forest: an application of the hedonic pricing method. Landscape and Urban Planning, 37(3), 211-222. DOI:10.1016/S0169-2046(97)80005-9

Tzoulas, K., Korpela, K., Venn, S., Yli-Pelkonen, V., Kaźmierczak, A., Niemela, J., \& James, P. (2007). Promoting ecosystem and human health in urban areas using Green Infrastructure: A literature review. Landscape and Urban Planning, 81(3), 167178. DOI:10.1016/j.landurbplan.2007.02.001

United Nations. (2014). World Urbanization Prospects: The 2014 Revision, Highlights. Department of Economic and Social Affairs. Population Division, United Nations.

Veitch, J., Carver, A., Abbott, G., Giles-Corti, B., Timperio, A., \& Salmon, J. (2015). How active are people in metropolitan parks? An observational study of park visitation in Australia. BMC public health, 15(1), 610. DOI:10.1186/s12889-0151960-6

Vickery, M. (1995). Gardens: the neglected habitat. In Ecology and conservation of butterflies (pp. 123-134): Springer. 
Wan, C., \& Shen, G. Q. (2015). Encouraging the use of urban green space: The mediating role of attitude, perceived usefulness and perceived behavioural control. Habitat International, 50, 130-139. DOI:10.1016/j.habitatint.2015.08.010

Wang, D., \& MacMillan, T. (2013). The Benefits of Gardening for Older Adults: A Systematic Review of the Literature. Activities, Adaptation \& Aging, 37(2), 153-181. DOI:10.1080/01924788.2013.78 4942

Wang, R., Zhao, J., \& Liu, Z. (2016). Consensus in visual preferences: The effects of aesthetic quality and landscape types. Urban Forestry \& Urban Greening, 20, 210-217. DOI:10.1016/j. ufug.2016.09.005

Whitford, V., Ennos, A. R., \& Handley, J. F. (2001). "City form and natural process"-indicators for the ecological performance of urban areas and their application to Merseyside, UK. Landscape and Urban Planning, 57(2), 91-103. DOI:10.1016/ S0169-2046(01)00192-X

Wolch, J. R., Byrne, J., \& Newell, J. P. (2014). Urban green space, public health, and environmental justice: The challenge of making cities 'just green enough'. Landscape and Urban Planning, 125, 234-244. DOI:10.1016/j.landurbplan.2014.01.017

Wright Wendel, H. E., Zarger, R. K., \& Mihelcic, J. R. (2012). Accessibility and usability: Green space preferences, perceptions, and barriers in a rapidly urbanizing city in Latin America. Landscape and Urban Planning, 107(3), 272-282. DOI:10.1016/j. landurbplan.2012.06.003

Zhang, W., Yang, J., Ma, L., \& Huang, C. (2015). Factors affecting the use of urban green spaces for physical activities: Views of young urban residents in Beijing. Urban Forestry \& Urban Greening, 14(4), 851-857. DOI:10.1016/j.ufug.2015.08.006 